\title{
Revisão teórica sobre o potencial da adição do óxido de grafeno em materiais cimentícios
}

\section{Theoretical review on the potential of graphene oxide addition in cementitious materials}

\author{
Vanessa Vilela Rocha ${ }^{1}$, Ricardo Augusto dos Santos Horta ${ }^{1}$, \\ Júnia Nunes de Paula ${ }^{1}$, Péter Ludvig ${ }^{1}$
}

\author{
${ }^{1}$ Programa de Pós-Graduação em Engenharia Civil CEFET-MG, Av. Amazonas, 7675, CEP: 30.510-000, Nova Game- \\ leira, Belo Horizonte, Minas Gerais, Brasil. \\ e-mail: vrvanessavilela@gmail.com, ricardocivi192@gmail.com,juniapaula@cefetmg.br, peter@cefetmg.br
}

\section{RESUMO}

O óxido de grafeno tem sido apontado como um material de reforço para compósitos de cimento. Além de ser um material com boa dispersão em água, ele apresenta elevado módulo de elasticidade, elevada resistência à tração, elevada superfície específica e alta condutividade térmica e elétrica. Visando aprofundar o conhecimento acerca do uso do óxido de grafeno em compósitos de cimento, o presente trabalho apresenta uma ampla revisão bibliográfica sobre os efeitos da adição do óxido de grafeno em compósitos de cimento Portland. A metodologia empregada para a seleção dos artigos acadêmicos foi o ProKnow-C, (Knowledge Development Process - Constructivist), ferramenta de revisão literária que permite a evidenciação do estágio atual do conhecimento acadêmico relacionado ao tema de estudo. Por meio desta metodologia de busca e seleção de artigos, foi possível selecionar, a partir de uma amostra bruta de 1354 artigos, os 47 artigos mais relevantes que apresentam as alterações nas propriedades mecânicas, no comportamento reológico e na microestrutura de compósitos de cimento com adição de óxido de grafeno, bem como técnicas de dispersão utilizadas. Dessa forma, as principais conclusões, as lacunas atuais de pesquisa e as oportunidades de estudo foram sumarizadas, constituindo uma base de referência para orientar trabalhos futuros envolvendo o uso de óxido de grafeno para a preparação de compósitos de cimento.

Palavras-chave: Óxido de grafeno. Cimento. Técnicas de Dispersão. Microestrutura. Propriedades mecânicas e reológicas.

\begin{abstract}
Graphene oxide has been pointed as a reinforcing material of cement composites. Besides being a material with good dispersion in water, it has a high modulus of elasticity, high tensile strength, high specific surface and high thermal and electrical conductivity. In order to deepen the knowledge about the use of graphene oxide in cement composites, this paper presents a wide bibliographic review on the effects of graphene oxide addition on Portland cement composites. The methodology used for the selection of academic articles was ProKnow-C, (Knowledge Development Process - Constructivist), a literary revision tool that allows the disclosure of the current stage of academic knowledge related to the study topic. By means of this method it was possible to select, from a crude sample of 1354 articles, the 47 most relevant articles that showed the changes in mechanical properties, rheological behavior and microstructure of cement composites with addition of graphene oxide, as well as dispersion techniques used. Thus, the main conclusions, current research gaps and study opportunities were summarized, constituting a reference base to guide future work involving graphene oxide.
\end{abstract}

Keywords: Graphene oxide. Cement. Dispersion techniques. Microstructure. Mechanical and rheological properties. 


\section{INTRODUÇÃO}

Nos últimos anos houve um interesse crescente da indústria e de órgãos do governo ligados à infraestrutura no desenvolvimento de materiais de construção mais resistentes e de maior durabilidade, capazes de reduzir o impacto ambiental das edificações.

Dentre estes materiais, destacam-se os compósitos de cimento reforçados com óxido de grafeno (OG). Como uma nova classe de nanomaterial em escala bidimensional, o OG tem recebido grande atenção em vários campos de aplicação na engenharia civil, devido ao seu potencial de reforço proporcionado pela elevada superfície específica [1], boa dispersão em água [2], elevada condutividade térmica e elétrica [3], bem como alta resistência à tração e flexão [4].

Visando o maior conhecimento sobre as pesquisas já realizadas envolvendo o uso do OG para preparação de compóstios de cimento, o presente trabalho, por meio do método ProKnow-C (Knowledge Development Process - Constructivist) desenvolvido pelo Laboratório de Metodologias Multicritério em Apoio à Decisão da Universidade Federal de Santa Catarina (LabMCDA/UFSC) [5-7], selecionou uma gama de artigos de prestígio cientifico e realizou uma análise bibliométrica completa e imparcial. Por meio deste trabalho foram identificadas as sugestões já apresentadas pelos pesquisadores e determinadas lacunas atuais de pesquisa que poderão nortear trabalhos futuros.

\section{REFERENCIAL TEÓRICO}

O OG é um nanomaterial que apresenta uma estrutura plana de átomos de carbono interligados em formato hexagonal, com orbitais hibridizados sp2 e sp3 [8]. Devido a presença de grupos funcionais de oxigênio, como hidroxila $(-\mathrm{OH})$, carboxila $(-\mathrm{COOH})$ e carbonilo $(\mathrm{C}=\mathrm{O})$ no plano basal e bordas de sua estrutura molecular é um material hidrofílico [9]. Pesquisas apontam que o OG pode proporcionar um elevado nível de reforço em materiais cimentícios em função de:

- Inter travamento da matriz do cimento, proporcionado pela morfologia rugosa do óxido de grafeno [4];

- Grupos funcionais de oxigênio (principalmente - $\mathrm{OH}$ e - $\mathrm{COOH}$ ) funcionam como sítios de adsorção tanto para moléculas de água como para componentes do cimento (C3A, C4AF, C3S e C2S), facilitando a reação de hidratação e formação dos cristais de C-S-H [1];

- Móleculas de água adsorvidas na superfície do oxido de grafeno constituem uma reserva de água e canais de transporte de água para hidratação futura do cimento, reduzindo a ocorrência de retração [10];

- O óxido de grafeno pode regular o processo de nucleação e formação de cristais de C-S-H em forma de flor, que aumenta consideravelmente a resistência de tração e flexão do compósito de cimento [11];

- As folhas de óxido de grafeno exibem duas dimensões em uma única estrutura que pode efetivamente deflexionar, capaz de absorver e transmitir os esforços de tração os quais o concreto é submetido. O processo ajuda a prevenir a iniciação e a propagação das fissuras em uma escala nanométrica [4];

- A adição do óxido de grafeno proporciona uma microestrutura com menos defeitos, o que está associado a uma condução mais eficiente de tensões térmicas na estrutura do compósito [3].

Dessa forma, as diferentes formas de atuação do OG como material de reforço na matriz de cimento apresentam-se resumidas, e o presente trabalho constitui uma base de referência em relação ao conteúdo de pesquisa já publicado e o que deve ser investigado futuramente sobre este nanomaterial.

\section{MÉTODO}

O método de seleção de portfólio bibliográfico ProKnow-C foi baseado nos trabalhos descritos por ENSSLIN et al. [5], CHAVES et al. [6], LACERDA [12], AZEVEDO [13] e WAICZYK et al.[14]. Suas etapas estão descritas na Tabela 1: 
Tabela 1: Etapas do processo de revisão literária Proknow-C.

\begin{tabular}{|c|c|}
\hline ETAPAS & CARACTERÍSTICAS DA ETAPA \\
\hline $\begin{array}{l}1^{\text {a }} \text { etapa: } \\
\text { Identificação do pro- } \\
\text { blema de pesquisa }\end{array}$ & $\begin{array}{l}\text { Determinação do problema de pesquisa. } \\
\text { Identificação das variáveis de interesse e palavras-chave relacionadas ao tema. }\end{array}$ \\
\hline $\begin{array}{l}2^{\text {a }} \text { etapa: } \\
\text { Seleção das bases de } \\
\text { dados }\end{array}$ & $\begin{array}{l}\text { Pesquisa das palavras-chave nas bases de dados relacionadas à área de Engenharia Civil. } \\
\text { Realização de duas buscas distintas: } \\
\text { i) busca com a combinação das palavras-chave graphene oxide e cement composite, para veri- } \\
\text { ficar as pesquisas envolvendo a influência do óxido de grafeno nos compósitos de cimento de } \\
\text { modo geral; } \\
\text { ii) busca com a combinação das palavras-chave graphene oxide, cement e microstructure, para } \\
\text { verificar as pesquisas envolvendo a influência do óxido de grafeno na microestrutura do cimen- } \\
\text { to hidratado. } \\
\text { Filtragem nos bancos de dados considerando: } \\
\text { Tipo do documento: artigo; } \\
\text { Linguagem: inglês; } \\
\text { Período: publicações dos últimos } 10 \text { anos; } \\
\text { Área do conhecimento: engenharia. }\end{array}$ \\
\hline $\begin{array}{l}3^{\text {a }} \text { etapa: } \\
\text { Filtragem do banco de } \\
\text { artigos bruto }\end{array}$ & $\begin{array}{l}\text { Seleção por títulos dos trabalhos alinhados com o tema de pesquisa. } \\
\text { Filtragem pelo software Mendeley (eliminação de títulos repetidos). } \\
\text { Busca do número de citações de cada artigo no Google Scholar, ordenando-os de maneira de- } \\
\text { crescente. Seleção dos artigos que apresentavam o acumulado de até } 85 \% \text { do total de citações } \\
\text { (maios reconhecimento científico). } \\
\text { Leitura dos resumos e escolha daqueles que são alinhados com o tema de pesquisa. }\end{array}$ \\
\hline $\begin{array}{l}4^{\mathrm{a}} \text { etapa: } \\
\text { Extração dos dados }\end{array}$ & $\begin{array}{l}\text { Coleta dos dados mais relevantes do portfólio bibliográfico obtido. } \\
\text { Ordenação, categorização e resumo dos dados coletados. }\end{array}$ \\
\hline $\begin{array}{l}5^{\text {a }} \text { etapa: Interpretação } \\
\text { dos resultados }\end{array}$ & $\begin{array}{l}\text { Análise das informações obtidas. } \\
\text { Análise de dados conflitantes. } \\
\text { Levantamento de lacunas de pesquisa existentes. } \\
\text { Discussão dos resultados encontrados. } \\
\text { Sugestão de pesquisas futuras. }\end{array}$ \\
\hline $\begin{array}{l}6^{\text {a }} \text { etapa: } \\
\text { Documentação }\end{array}$ & Apresentação das etapas percorridas e principais resultados evidenciados. \\
\hline
\end{tabular}

Por meio das seis etapas do processo de seleção de artigos descrito anteriormente, foram obtidos os seguintes resultados, expressos na Tabela 2. Os dados foram coletados em janeiro de 2019.

Tabela 2: Resultado do processo de busca e seleção de artigos nas bases de dados.

\begin{tabular}{l|c|c|c|c|c}
\hline PALAVRAS-CHAVE & $\begin{array}{c}\text { ARTIGOS } \\
\text { ENCON- } \\
\text { TRADOS }\end{array}$ & $\begin{array}{c}\text { ARTIGOS } \\
\text { COM TítULO } \\
\text { ALINHADO }\end{array}$ & $\begin{array}{c}\text { ARTIGOS } \\
\text { APÓS ELI- } \\
\text { MINAÇÃO DE } \\
\text { REPETIÇÕES }\end{array}$ & $\begin{array}{c}\text { ARTIGOS COM } \\
\text { TíTULO ALI- } \\
\text { NHADO E RE- } \\
\text { CONHECIMENTO } \\
\text { CIENTÍFICO }\end{array}$ & $\begin{array}{c}\text { ARTIGOS COM } \\
\text { TíTULO E RESU- } \\
\text { MO ALINHADOS E } \\
\text { RECONHECIMEN- } \\
\text { TO CIENTÍFICO }\end{array}$ \\
\hline $\begin{array}{l}\text { Graphene oxide; ce- } \\
\text { ment composites }\end{array}$ & 954 & 160 & 75 & 22 & 13 \\
\hline $\begin{array}{l}\text { Graphene oxide; ce- } \\
\text { ment; microstructure }\end{array}$ & 400 & 66 & 53 & 35 & 34 \\
\hline \multicolumn{7}{l}{\begin{tabular}{l} 
Total de artigos selecionados (portfólio bibliográfico): \\
\hline
\end{tabular}}
\end{tabular}

Visando analisar sistematicamente os 47 artigos selecionados, e de forma a identificar as principais conclusões e oportunidades (lacunas atuais de pesquisa) dos artigos, foram definidas 4 lentes de pesquisa, as quais são identificadas na Tabela 3. Essas lentes de pesquisa envolvem o foco dado a busca de informações relacionadas a presença de $(\mathrm{OG})$ nos compósitos de cimento. 
Tabela 3: Lentes de pesquisa utilizadas na análise sistêmica do portfólio bibliográfico.

\begin{tabular}{l|l|l}
\hline ID & LENTES & O QUE PROCURAR \\
\hline 1 & Métodos de dispersão & Quais métodos foram empregados para a dispersão do OG na matriz cimentícia? \\
\hline 2 & Microestrutura & $\begin{array}{l}\text { Como a adição do OG interfere na microestrutura do compósito cimentício, em ter- } \\
\text { mos do arranjo cristalino e grau de porosidade? }\end{array}$ \\
\hline 3 & Comportamento reológico & $\begin{array}{l}\text { Como a introdução do OG influenciou nas propriedades reológicas (trabalhabilidade, } \\
\text { fluidez, tensão de escoamento) do compósito cimentício? }\end{array}$ \\
\hline 4 & Propriedades mecânicas & $\begin{array}{l}\text { Quais foram os ganhos obtidos nas propriedades mecânicas (módulo de elasticidade, } \\
\text { resistências à compressão, tração e flexão) dos compósitos cimentícios com adição } \\
\text { de OG? }\end{array}$ \\
\hline
\end{tabular}

Cada uma destas lentes retrata uma perspectiva diferente de estudo e juntas elas fornecem o estado atual de conhecimento sobre os principais efeitos da adição do óxido de grafeno em compósitos de cimento.

\section{RESULTADOS E DISCUSSÕES}

Dos artigos selecionados, $60 \%$ realizaram análises com pasta de cimento, 36\% utilizaram argamassas e $4 \%$ fizeram análises com ambos, porém, nenhum dos artigos apresentou estudos utilizando o concreto.

A Figura 1 apresenta o ano de publicação dos artigos que compõem o portfólio bibliográfico. Apesar do método Proknow-C ter limitado a coleta de dados para os trabalhos realizados nos últimos 10 anos, observou-se que $62 \%$ destes tiveram publicação nos últimos dois anos. Esses resultados mostram o crescente interesse do uso do OG para preparação de compósitos de cimento e seu grande potencial de aplicação na indústria da construção civil.

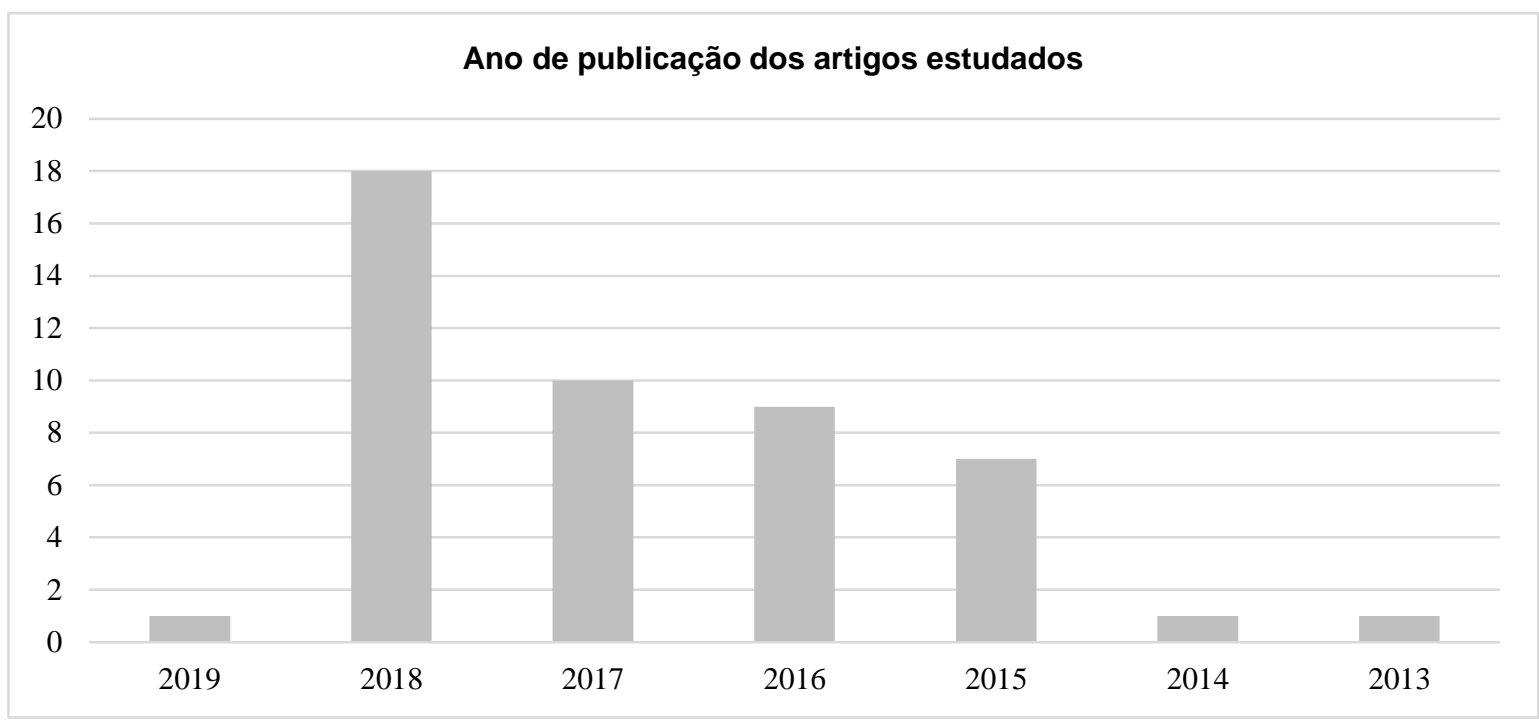

Figura 1: Ano de publicação dos artigos que compõem o portfólio bibliográfico.

Nos tópicos seguintes são apresentadas as principais informações extraídas dos artigos selecionados, sob a ótica de cada uma das lentes de pesquisa definidas anteriormente.

\subsection{Métodos de dispersão}

O OG apresenta grupos funcionais de oxigênio, como hidroxila $(-\mathrm{OH})$, carboxila $(-\mathrm{COOH})$ e carbonilo $(\mathrm{C}=\mathrm{O})$ no plano basal e bordas de sua estrutura molecular, que interagem com as moléculas de água permitindo a sua maior dispersão em meio aquoso [9]. Desta forma, nos artigos analisados o OG já se encontra diluído na própria água utilizada para a preparação do compósito de cimento.

Por meio do portfólio bibliográfico analisado, no entanto, percebe-se que, antes da preparação dos compósitos de cimento, a solução aquosa com OG é submetida à frequência ultrassônica, agitação mecânica ou tratamento de superfície com plastificante, de forma a promover uma esfoliação mais eficiente e consequente separação das nano folhas de OG.

A Figura 2 a seguir apresenta os métodos de dispersão adotados. 


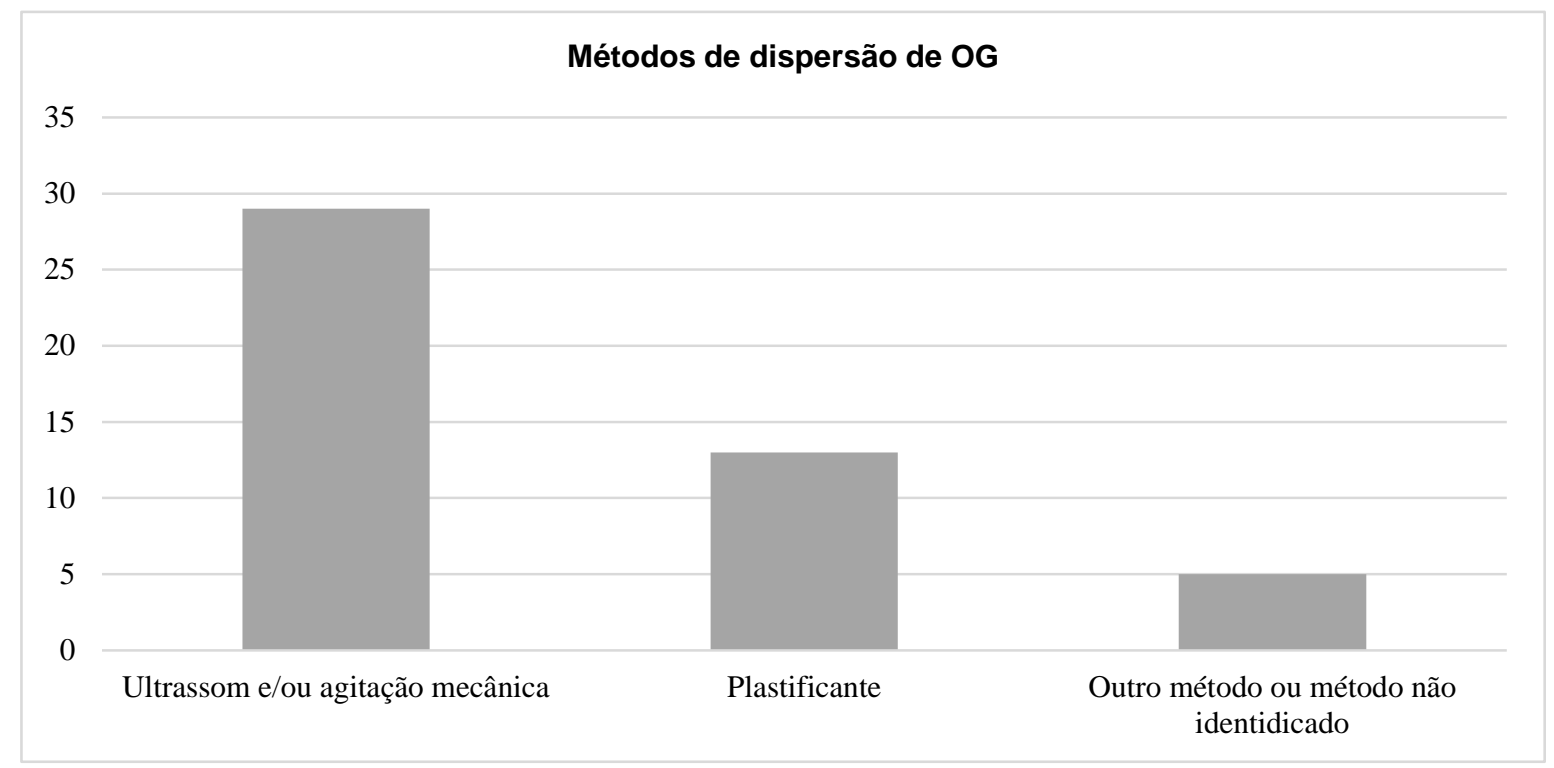

Figura 2: Métodos de dispersão do OG aplicados nos artigos que compõe o portfólio bibliográfico.

Um percentual equivalente a $62 \%$ dos artigos analisados, apresentam a dispersão do óxido de grafeno por meio de frequências ultrassônicas e/ou agitação mecânica. Por meio de tal metodologia, de modo geral, os artigos sugerem eficácia na dispersão, e como resultado apontam boa dispersão e interação com a matriz do cimento [15], o que contribui para a redução de porosidade [16, 17], densificação da microestrutura [17] e nucleação da reação de hidratação do cimento [1].

LV et al. [18] utilizaram frequências ultrassônicas com duração de 20-60 min para a dispersão de soluções aquosas contendo 0,01, 0,02, 0,03, 0,04, 0,05 e 0,06\% de OG.

LIU, et al. [19] dispersaram $0.03 \%$ de OG juntamente a $1,5 \%$ de nano sílica em ultrassom e agitação mecânica para preparação de pasta de cimento. Por meio das análises os autores concluíram que os nanomateriais estavam bem dispersos.

LI X., et al. [20] dispersaram $0.01 \%, 0.02 \%, 0.03 \%$, e $0.04 \%$ de OG em solução aquosa em concentração de 4 mg.m-1 ${ }^{1}$, ultrassonizada por 5 minutos e também apontaram presença de aglomerações.

LU Z., et al. [21] utilizaram ultrassom e agitador magnético para dispersar 0,05\% de OG juntamente a sílica, e como resultado da combinação de ambos na matriz de cimento foi registrado aglomeração, apesar da presença de sílica contribuir para a melhor dispersão do OG em água.

Por outro lado, o uso de plastificantes como método de dispersão de OG representam $27 \%$ dos artigos analisados. ZHAO, et al. [22] investigaram o comportamento das pastas de cimento preparada por meio de dispersão de OG em diferentes agentes redutores de água: lignosulfonato, policondensado de naftaleno sulfonato formaldeído (PNS) e policarboxilato. Como resultado neste trabalho, o processo de dispersão com policarboxilato se mostrou mais eficaz.

GAO, et al. [23] dispersaram OG e nanotubos de carbono (NTC's) em solução aquosa com policarboxilato e frequência ultrassônica. Os autores ressaltam a importância de ultrassonicação suficiente para evitar estrutura porosa. ZHAO, et al. [22] também apontam que o aditivo a base de policarboxilato é capaz de atingir completa dispersão do OG na solução alcalina da pasta de cimento.

ZHOU, et al. [24] também dispersaram OG e NTC's em solução aquosa com policarboxilato em frequência ultrassônica a afirmam que o OG também atua como um dispersante para os NTC's.

A proporção de OG utilizada ainda é baixa, e não ultrapassa $6,4 \%$ do peso total do cimento [15]. $77 \%$ do material estudado, o que representa 36 artigos analisados, variou a proporção de OG. Desses 36 artigos, 22 identificaram um teor percentual ótimo de OG baseado nas pesquisas realizadas, e os resultados do teor ótimo identificado encontra-se descritos na Figura 3. 


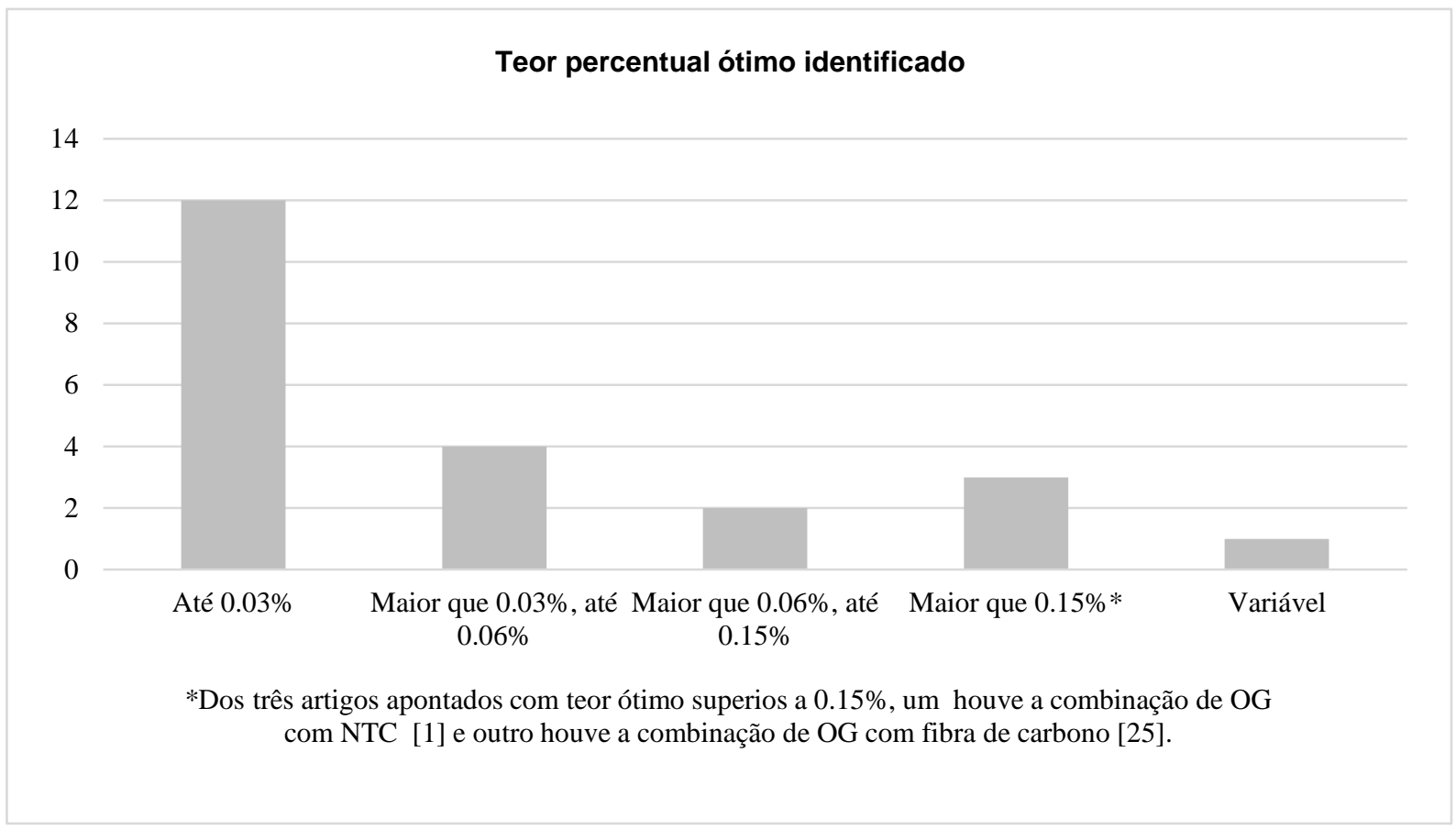

Figura 3: Teor percentual ótimo identificado nos artigos que compõe o portfólio bibliográfico.

Nota-se que a adição de teores em até $0.03 \%$ de OG soma quase $56 \%$ dos indicativos de teor ótimo, sugerindo que esse valor é um bom ponto de partida para futuras pesquisas. Além disso, percebe-se que quando o OG é combinado com outros nanomateriais de carbono, o teor ótimo apontado é superior, resultando em $1.5 \%$ de OG em presença de $0.5 \%$ de NTC [1], que resultou em $72.7 \%$ de ganho na resistência a tração na flexão, e $1 \%$ de OG com $1 \%$ de fibra de carbono [25] apontou $43.6 \%$ de ganho também na resistência a tração na flexão. A combinação dos elementos pode sugerir que em presença de outros elementos de carbono ou é necessária maior quantidade de OG para alcançar ganhos de resistência, ou propicia a uma melhor dispersão, o que permite maior concentração de OG. Essa verificação pode ser apontada como uma oportunidade de pesquisa.

\subsection{Microestrutura}

A presença de materiais em nano escala tem sido estudada pela sua capacidade de preencher os poros na matriz do cimento, tornando a microestrutura mais densa e compacta, o que favorece o aumento na resistência mecânica dos materiais cimentícios [9].

O microscópio eletrônico de varredura (MEV) é o instrumento de observação mais utilizado para análises microscópicas, em função de seu alto grau de resolução das imagens, sendo encontrado em $91 \%$ dos trabalhos identificados na literatura. Menos usual, mas também utilizado, o microscópio de força atômica (AFM) está presente em $11 \%$ dos artigos analisados. Por meio da varredura de superfície, esta técnica fornece um dado que as outras técnicas não são capazes de fornecer, que é a geração de imagens topográficas com resolução atômica da superfície de uma amostra. O microscópio eletrônico de transmissão totaliza $13 \%$ dos trabalhos analisados.

Por meio das imagens geradas, os autores verificaram qualitativamente o processo de hidratação em presença do OG, e é observado os produtos de hidratação do cimento sendo formado na superfície do OG [21, 26, 27], o que comprova a atuação do nanomaterial como ponto de nucleação dos produtos de hidratação. Além disso, as imagens microscópicas permitem a visualização dos produtos de hidratação mais densos em presença de OG $[18,26]$.

Para corroborar os resultados das imagens microscópicas que evidenciam a influência do OG na microestrutura dos compósitos de cimento, análises de porosimetria por intrusão de mercúrio (MIP), termogravimetria (TGA), espectroscopia Raman, infravermelho com transformada de Fourier (FTIR), difração de raios-X (DRX) e adsorção de nitrogênio.

As análises de porosimetria realizadas apontaram refinamento dos poros [16, 19, 20, 22, 23, 28]. De acordo com GONG, et al. [16] a porosidade total pode ser reduzida em até $13,5 \%$ e ainda de acordo com HE, 
et al. [29] a presença de OG diminui a absorção de água e a permeabilidade do material cimentício às substâncias gasosas, o que reduz a entrada de agentes agressivos no concreto e previne a corrosão da armadura, contribuindo efetivamente para a ampliação da durabilidade das estruturas na construção civil.

Relacionado à redução de porosidade, análises de TGA destacam que em presença de OG há a redução da carbonatação dos compósitos [8, 29]. Aprofundando o estudo do processo de hidratação durante a carbonatação, as análises de TGA realizadas por LONG, et al. [30] apontam que a dissolução de C-H e a descalcificação de C-S-H, são suprimidas com adição de OG durante os primeiros estágios de carbonatação.

LV, et al. [31], ainda por meio de análises microscópicas, FTIR e porosimetria afirmam que a presença de OG tem efeitos de autocorreção para os buracos e fissuras para compósitos de cimento.

As análises de espectroscopia Raman, DRX e FTIR foram utilizadas para a caracterização do nanomaterial utilizado, e são utilizadas em $12 \%, 25 \%$ e $37 \%$ dos artigos analisados no presente trabalho, respectivamente. O FTIR [32] e o DRX [1, 8, 32] aparecem em alguns artigos como método de análise dos compósitos de cimento.

LI G. et al. [33] por meio de análises em DRX afirmam ainda que a presença de OG pode promover formação de etringita. YANG et al. [32] que além da realização das análises de FTIR e DRX nas pastas de cimento, realizaram análise química XPS, TGA e MEV e apontam que a presença de OG não alterou a microestrutura do C-S-H e as melhorias nas propriedades mecânicas vieram principalmente da aceleração do grau de hidratação e das reações químicas. Já LONG et al. [28] por meio de análises de nano-indentação, conseguiu classificar o C-S-H em critérios de baixa e alta densidade, e concluiu que a presença de OG aumenta o volume de $\mathrm{C}-\mathrm{S}-\mathrm{H}$ de alta densidade.

De acordo com ZHAO et al. [34] os resultados conflitantes sobre a influência do OG no processo de hidratação revelam a natureza complexa dos géis de C-S-H modificados por esse nanomaterial, e as divergências de resultados podem ser atribuídas aos diferentes estados de dispersão das folhas de OG na matriz de cimento.

MOHAMMED et al. [8] por meio de análises em DRX, verificaram que pastas de cimento com OG apresentam menor quantidade de hidróxido de cálcio do que a referência. Além disso, foram identificados altos picos de calcita $\left(\mathrm{CaCO}_{3}\right)$ na pasta de cimento com adição de OG, o que corresponde a uma menor reação de carbonatação em presença do nanomaterial. As análises das isotermas obtidas por meio da adsorção de nitrogênio suportam os resultados obtidos em relação a influência do OG na carbonatação. As isotermas de adsorção das pastas sem OG, no início do período de carbonatação (3 meses), encolheram levemente em relação ao seu estado inicial antes de iniciar a carbonatação, o que pode ser justificado pela diminuição do volume de microporos.

Análises da adsorção de nitrogênio também foram realizadas por ZHAO et al. [34], e os resultados obtidos apontaram que, com a adição de OG, o número de poros de gel, especialmente os poros com diâmetro de até 4 nanômetros, foram reduzidos significativamente em relação à amostra de referência, conforme indicado na Figura 4, resultado da análise realizada pelos autores. 

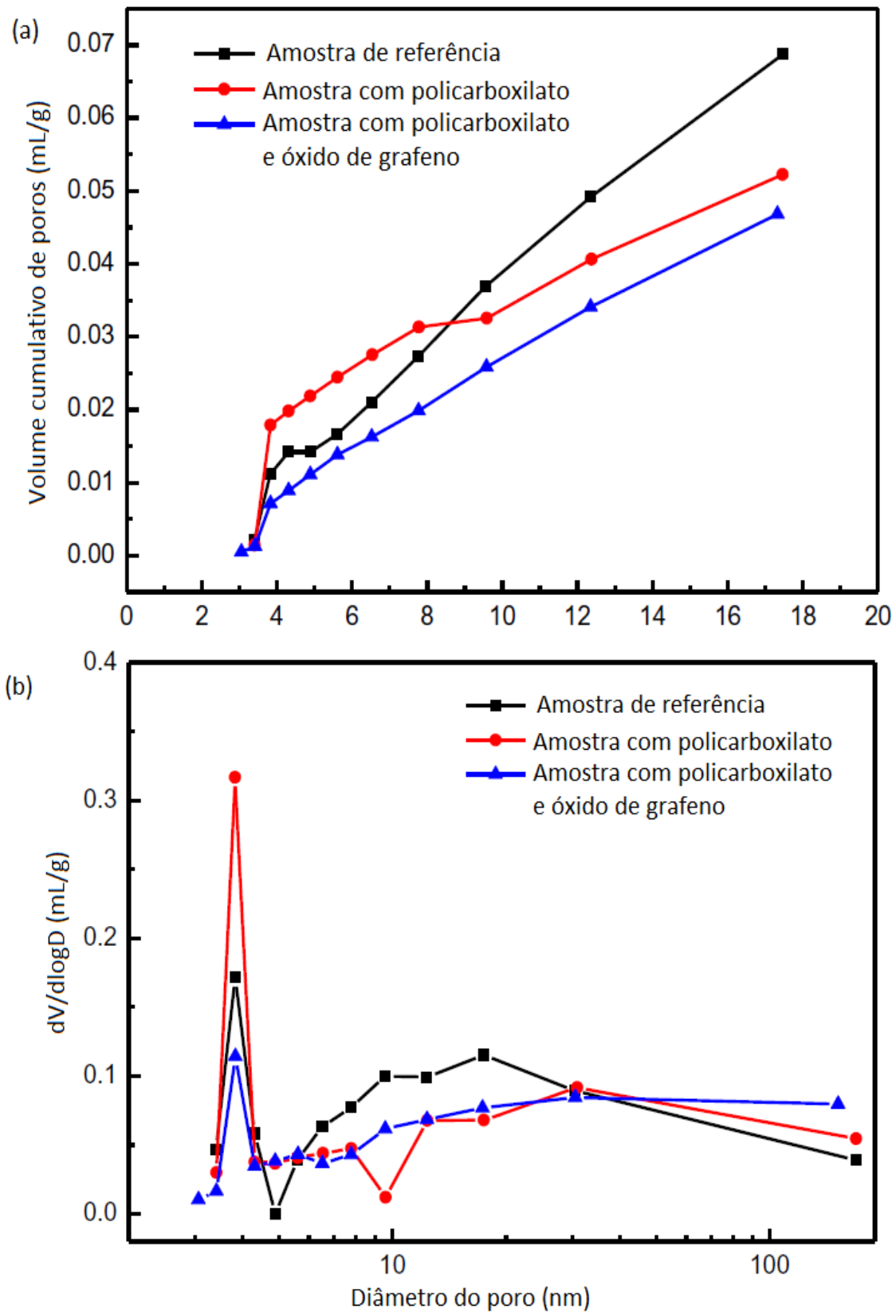

Figura 4: Resultado da análise de adsorção de nitrogênio realizada por ZHAO et al. [34] indicando redução de poros de até 4 nanômetros em presença de OG. Fonte: Adaptado de ZHAO et al. [34].

\subsection{Comportamento reológico}

Devido ao fato do óxido de grafeno ser um nanomaterial com elevada superfície específica, a sua adição aos compósitos de cimento gera um aumento na demanda de água livre e consequentemente altera o comportamento destes materiais no estado fresco (comportamento reológico), aumentando parâmetros como viscosidade e tensão de escoamento e reduzindo a trabalhabilidade. Mesmo diante deste fato, apenas $10 \%$ dos artigos analisados realizaram testes reológicos nas amostras com OG, sendo apontadas reduções significativas na trabalhabilidade dos compósitos de cimento com adição de OG em relação às amostras de referência [4, 16, 30, 35].

De acordo com PAN et al. [4] a presença de $0,05 \%$ de OG aumenta a área superficial em $237 \%$, fato que justifica a redução da plasticidade. Por meio do ensaio do mini-slump, a presença de $0.05 \%$ de OG pode impactar na redução da fluidez em até $41.7 \%$.

Para garantir a fluidez dos compósitos, em torno de $66 \%$ dos artigos analisados apresentaram o uso de algum tipo de plastificante, o que resulta em 28 artigos. Desses 31 artigos que fazem uso de aditivos plastifi- 
cantes, apenas 3 artigos não informaram o tipo de plastificante ou utilizam o aditivo diferente do policarboxilato. Esse resultado é condizente com os resultados do estudo de ZHAO et al. [22], no qual o policarboxilato é a base de plastificante mais recomendada para a dispersão do OG.

Além da influência na plasticidade, o ensaio de calorimetria mostrou que a presença de $0,05 \%$ OG reduziu o calor de hidratação em até 54\% [36]. No entanto, é apontado que o OG sugere mudanças na cinética da reação de hidratação [15]. A taxa de hidratação do cimento é aumentada em presença de OG [19, 32, 37] e, como consequência, a carbonatação da Portlandita $(\mathrm{CH})$ e do silicato-hidrato de cálcio $(\mathrm{C}-\mathrm{S}-\mathrm{H})$ foi inibida durante as primeiras idades de carbonatação devido a esse aumento do grau de hidratação [30]. Além disso, o OG também é apontado como sendo ponto de nucleação das reações de hidratação [10, 26, 27, 38], porém proporções de OG superiores a $0.125 \%$ podem inibir a hidratação [40], uma justificativa para que $55 \%$ dos artigos que informam o teor ótimo apresentarem indicativos de que essa proporção deve ser inferior a $0,03 \%$.

Dos artigos analisados, no entanto, não foi apresentado nenhum trabalho que verifica a influência do OG no tempo de pega dos compósitos de cimento, sendo esta uma área que requer estudos sistemáticos para determinação da influência da adição de carga na matriz de cimento. A ausência desta propriedade nos artigos encontrados é devida ao processo de busca do ProKnow-C, que pode ser bastante restritivo em algumas situações. Este fato, no entanto, não invalida o método, sendo necessária a exploração do tema de interesse por meio de outras palavras chave, tornando a busca mais avançada.

\subsection{Propriedades mecânicas}

GONG et al. [16] realizaram testes sobre uma pasta de cimento de referência e uma pasta de cimento com $0,03 \%$ de OG por peso de cimento. Foram obtidos ganhos de $46 \%$ e $50 \%$ nas resistências à compressão e tração direta, respectivamente, aos 28 dias, nas pastas de cimento com adição de OG. Os autores apontam como possíveis causas para os ganhos estruturais obtidos o aumento no grau de hidratação do cimento, a redução da porosidade total e o refinamento da estrutura porosa pela adição de OG.

HORSZCZARUK et al. [15] analisaram o aumento no módulo de elasticidade de pastas de cimento reforçadas com $3 \%$ de OG, em relação à amostra de controle. O módulo de elasticidade aumentou de 1-10 Mpa para 5-20 Mpa. O estudo realizado mostrou que a cinética da reação de hidratação não foi alterada significativamente pela adição de OG, além disto, este material apresentou boa dispersão e interação com a matriz do cimento.

HOU et al. [2] investigaram a resistência à compressão e a resistência à tração na flexão de pastas de cimento com adição de $0,16 \%$ de $\mathrm{OG}$, além da pasta de cimento de referência. Os aumentos nas resistências à compressão e tração na flexão foram de 3,21\% e 11,62\%, respectivamente, aos 14 dias. As melhorias obtidas foram atribuídas ao maior grau de hidratação, efeito nano-filler e efeito ponte de ligação provenientes da adição de OG. Os resultados encontrados neste artigo diferem dos resultados encontrados por SHARMA et al.; [40], que apontou inibição do processo de hidratação para teores de OG superiores a 0,125\%. Essa divergência de resultado se deve às diferenças nas características físicas e químicas dos óxidos de grafeno utilizados na literatura. Como o método de produção do OG apresenta bastantes peculiaridades, variando conforme a patente de produção, o produto final também apresenta uma variação intrínseca em suas propriedades mecânicas.

LV et al. [31] realizaram testes com uma pasta de cimento de referência e pastas de cimento com adição de $0,01-0,05 \%$ de OG. O teor ótimo de adição foi de $0,03 \%$ de OG. Foram obtidos aumentos de 56,5\% e $77,6 \%$ nas resistências à compressão e tração na flexão, respectivamente, aos 28 dias. A partir dos resultados encontrados, os autores inferiram que a adição de OG junto ao superplastificante pode controlar completamente a forma de agregação dos cristais de hidratação do cimento. Os cristais em formato de flor e poliedros têm a capacidade de reparar buracos e fissuras nos compósitos de cimento.

PAN et al. [4] realizaram testes sobre uma pasta de cimento de referência e uma pasta de cimento com $0,05 \%$ de OG por peso de cimento. Foram observados aumentos na resistência à compressão e resistência à tração na flexão de $15-33 \%$ e $41-58 \%$, respectivamente, aos 28 dias. Entre as possíveis razões para isto, destacam-se: inter-travamento mecânico proporcionado pela morfologia rugosa do OG, forte interação entre as fissuras e as folhas de $\mathrm{OG}$ devido à geometria $2 \mathrm{D}$ e elevada superfície específica, promoção do processo de hidratação e formação de fortes forças interfaciais ente grupos carboxílicos do OG e produtos de hidratação do cimento.

WANG et al. [36] investigaram a resistência à compressão e a resistência à tração na flexão de uma pasta de cimento de referência e pastas de cimento com adição de 0,01-0,05\% de OG. O teor ótimo de adição do OG foi de $0,05 \%$, sendo obtidos aumentos de $40,4 \%$ na resistência à compressão e de $90,5 \%$ na resistência à tração na flexão, aos 28 dias. As causas para os ganhos estruturais obtidos foram: aceleração do processo de 
nucleação, crescimento e separação dos produtos de hidratação, promoção da reação de hidratação, alinhamento regular dos cristais e densificação da microestrutura.

LU et al. [9] realizaram testes de resistência à compressão, tração direta e tração na flexão de argamassas com $0,05 \%, 0,08 \%$ e $0,12 \%$ de OG, além da amostra utilizada como controle. O teor ótimo de adição foi de $0,08 \%$, sendo obtidos aumentos de $24,8 \%, 37,7 \%$ e $80,6 \%$ nas resistências à compressão, tração direta e tração na flexão, respectivamente, aos 28 dias. As razões apontadas para os resultados obtidos foram: redução da porosidade total, aumento na tenacidade pelo intertravamento no nível da nano escala e melhoria das ligações entre as fibras de PVA e a matriz do cimento pela adição de OG.

LV et al. [11] avaliaram as resistências de compressão, tração direta e tração na flexão de argamassas com $0,01-0,05 \%$ de OG e outra utilizada como controle. O teor ótimo de adição foi de $0,03 \%$, sendo obtidos aumentos de 38,9\%,78,6\% e 60,7\% nas resistências à compressão, tração direta e tração na flexão, respectivamente, aos 28 dias. Os resultados obtidos sugerem que as folhas de OG são capazes de regular a formação de cristais hidratados em forma de flor, aumentando a resistência à tração/flexão/compressão do cimento.

SHARMA \& KOTHIYAL [40] investigaram a influência do tamanho das folhas de OG sobre a resistência à compressão de argamassas reforçadas com sílica ativa, cinza volante e PVA. Foram preparadas amostras com 0,125-1,0\% de OG-a (14 $\mathrm{nm}$ de espessura e tamanho médio das folhas de $900 \mathrm{~nm}$ ) e 0,125 1,0\% de OG-b ( $3 \mathrm{~nm}$ de espessura e tamanho médio das folhas de $100 \mathrm{~nm}$ ), além da amostra de controle. Foram obtidos ganhos de 63,3\% e 86,3\%na resistência à compressão para OG-a e OG-b, respectivamente, aos 28 dias. Os resultados obtidos permitem inferir que a moagem mecânica do OG aumenta o seu potencial de contribuições sobre as propriedades mecânicas do compósito cimentício devido ao aumento na área superficial.

TONG et al. [17] realizaram estudos da resistência à compressão de uma argamassa com 0,1\% de OG, além argamassa de referência. $\mathrm{O}$ aumento verificado na resistência à compressão com a adição de $\mathrm{OG}$ foi de 10,2- 13,2\%, aos 28 dias. As razões para os ganhos estruturais obtidos foram: reordenação da microestrutura, melhoria das interações na zona de interface, decrescimento da porosidade e dos cristais de C-S-H de baixa densidade e crescimento dos cristais de C-S-H de alta densidade (densificação da microestrutura).

WANG et al. [36] investigaram a resistência à compressão e a resistência à tração na flexão de argamassas com 0,01-0,05\% de OG, bem como da argamassa de referência, aos 28 dias. O teor ótimo de adição do OG foi de $0,05 \%$, sendo obtidos aumentos de $24,4 \%$ na resistência à compressão e de $70,5 \%$ na resistência à tração na flexão, aos 28 dias.

WANG et al. [41] realizaram testes sobre uma argamassa de referência e argamassas com adição de 0,01-0,05\% OG. O teor ótimo de adição foi de $0,03 \%$, sendo obtidos aumentos de $18,79 \%$ e $56,62 \%$ nas resistências à compressão e tração na flexão, respectivamente, aos 28 dias. Foi observado que as folhas de OG se conectam uma a outra formando uma estrutura em três dimensões, enquanto os produtos de hidratação são inseridos nessa estrutura.

ZHAO, LI et al [22] realizaram testes sobre uma argamassa de referência e outra com 0,022\% de OG. Foram obtidos aumentos de $17,68 \%$ e $22,55 \%$ nas resistências à compressão e tração na flexão, respectivamente, aos 28 dias. Os ganhos estruturais obtidos podem ser explicados pelo aumento no grau de hidratação, melhor eficiência na transferência de cargas, microestrutura compacta e controle da iniciação e propagação das fissuras na nano escala.

ZHAO et al. [42] realizaram testes com uma argamassa de referência e argamassas com adição de 0,011-0,066\% de OG. Foram obtidos aumentos de 22,59\% e 24,56\% nas resistências à compressão e tração na flexão, respectivamente, além de aumento de $32,37 \%$ no módulo de Young, aos 28 dias. Os resultados mostram que a adição de OG restringe a iniciação e a propagação das fissuras, de modo que elas ocorrem de maneira tortuosa e com menor espessura.

A Tabela 4 sintetiza os principais resultados encontrados nos trabalhos analisados: 
Tabela 4: Resumo dos principais resultados encontrados no portfólio bibliográfico.

\begin{tabular}{|c|c|c|c|c|c|c|c|c|}
\hline \multirow[b]{2}{*}{ ID } & \multirow[b]{2}{*}{ AUTOR } & \multirow[b]{2}{*}{ DISPERSÃO } & \multirow[b]{2}{*}{$\begin{array}{l}\text { TEOR DE } \\
\text { OG }\end{array}$} & \multirow[b]{2}{*}{$\begin{array}{l}\text { FA- } \\
\text { TOR } \\
\text { A/C }\end{array}$} & \multicolumn{4}{|c|}{$\begin{array}{l}\text { AUMENTO (\%) EM RELAÇÃO ÀS AMOSTRAS DE CON- } \\
\text { TROLE }\end{array}$} \\
\hline & & & & & $\begin{array}{l}\text { RESISTÊN- } \\
\text { CIA À COM- } \\
\text { PRESSÃO }\end{array}$ & $\begin{array}{l}\text { RESIS- } \\
\text { TÊNCIA À } \\
\text { TRAÇÃO } \\
\text { DIRETA }\end{array}$ & $\begin{array}{l}\text { RESISTÊNCIA } \\
\text { À TRAÇÃO NA } \\
\text { FLEXÃO }\end{array}$ & $\begin{array}{l}\text { MÓDULO } \\
\text { DE ELAS- } \\
\text { TICIDADE }\end{array}$ \\
\hline 1 & $\begin{array}{l}\text { CHEN et } \\
\text { al. [25] }\end{array}$ & $\begin{array}{l}\text { Solução } \\
\text { aquosa }\end{array}$ & $\begin{array}{c}0,04,0,06, \\
0,08,0,2, \\
0,4,0,6, \\
0,8,1,0 \% \\
\text { de OG e } \\
1 \% \text { de } \\
\text { fibra de } \\
\text { carbono }\end{array}$ & 0,37 & $\begin{array}{c}23,89 \% \text { com } \\
\text { OG e fibra de } \\
\text { carbono }\end{array}$ & - & $\begin{array}{l}138,44 \% \mathrm{com} \\
\text { OG e fibra de } \\
\text { carborno. }\end{array}$ & - \\
\hline 2 & $\begin{array}{l}\text { GAO et } \\
\text { al. [23] }\end{array}$ & $\begin{array}{l}\text { OG e NTC } \\
\text { dispersos em } \\
\text { água, poli- } \\
\text { carboxilato e } \\
\text { frequência } \\
\text { ultrassônica } \\
\end{array}$ & $\begin{array}{l}\text { Aproxi- } \\
\text { madamen- } \\
\text { te } 0,03 \%\end{array}$ & 0,4 & - & - & $78,80 \%$ & $53,20 \%$ \\
\hline 3 & $\begin{array}{l}\text { GONG et } \\
\text { al. }[16]\end{array}$ & $\begin{array}{c}\text { Ultrassom e } \\
\text { agitador me- } \\
\text { cânico }\end{array}$ & $0.03 \%$ & 0.5 & $46,00 \%$ & $50,00 \%$ & - & - \\
\hline 4 & $\begin{array}{l}\text { HE } \text { et al. } \\
\text { [29] }\end{array}$ & $\begin{array}{c}\text { Solução } \\
\text { aquosa e } \\
\text { ultrassom em } \\
\text { três concen- } \\
\text { trações: } 0,25 \\
\text { g / L, } 0,5 \text { g / } \\
\text { L e } 1 \mathrm{~g} / \mathrm{L} \\
\end{array}$ & - & 0,3 & $\begin{array}{l}10.8 \% \text { de } \\
\text { ganho com } \\
\text { tratamento de } \\
\text { superfície } \\
\text { com OG }\end{array}$ & - & - & - \\
\hline 5 & $\begin{array}{l}\text { HORS- } \\
\text { ZCZA- } \\
\text { RUK et } \\
\text { al. [15] }\end{array}$ & Ultrassom & $3,00 \%$ & 0,57 & - & - & - & $\begin{array}{c}\text { Aumento de } \\
\text { 1-10 Mpa } \\
\text { para 5-20 } \\
\text { MPa }\end{array}$ \\
\hline 6 & $\begin{array}{l}\text { HOU et } \\
\text { al. [2] }\end{array}$ & $\begin{array}{l}\text { Agitador } \\
\text { mecânico }\end{array}$ & $0,16 \%$ & - & $3,21 \%$ & - & $11,62 \%$ & - \\
\hline 7 & $\begin{array}{l}\text { LI G.et } \\
\text { al. [33] }\end{array}$ & $\begin{array}{c}\text { Plastificante } \\
\text { em solução } \\
\text { aquosa } \\
\end{array}$ & $\begin{array}{l}0,01 \% \text { a } \\
0,05 \%\end{array}$ & 0,3 & - & - & $\begin{array}{c}40 \% \text { com } \\
0,03 \%\end{array}$ & - \\
\hline 8 & $\begin{array}{l}\text { LI X.et } \\
\text { al. [43] }\end{array}$ & $\begin{array}{c}\text { Solução } \\
\text { aquosa e } \\
\text { ultrassom } \\
\end{array}$ & $\begin{array}{c}0,02,0,04, \\
0,06, \mathrm{e} \\
0,08 \% \\
\end{array}$ & 0,4 & $\begin{array}{c}46,8 \% \text { com } \\
0.08 \%\end{array}$ & - & $\begin{array}{c}14,2 \% \text { com } \\
0.04 \%\end{array}$ & - \\
\hline 9 & $\begin{array}{l}\text { LI X.et } \\
\text { al. [37] }\end{array}$ & $\begin{array}{c}\text { Água em } \\
\text { concentração } \\
4 \mathrm{mg} / \mathrm{ml} .\end{array}$ & $\begin{array}{c}0,1 \%, \\
0,15 \% \text { e } \\
0,20 \%\end{array}$ & 0,4 & - & $\begin{array}{l}67 \% \text { com } \\
0,04 \%\end{array}$ & - & - \\
\hline 10 & $\begin{array}{c}\text { LI X.et } \\
\text { al. } \\
{[20]}\end{array}$ & $\begin{array}{l}\text { Suspensão } \\
\text { aquosa de } \\
\text { OG (4 } \\
\text { mg/ml) ul- } \\
\text { trassonizada } \\
\text { por } 5 \text { minu- } \\
\text { tos } \\
\end{array}$ & $\begin{array}{c}0,01 \%, \\
0,02 \%, \\
0,03 \%, \mathrm{e} \\
0,04 \%\end{array}$ & 0,4 & - & - & $\begin{array}{l}83 \% \text { com } \\
0,04 \%\end{array}$ & - \\
\hline 11 & $\begin{array}{c}\text { LI X.et } \\
\text { al. } \\
\text { [44] }\end{array}$ & $\begin{array}{c}\text { Solução } \\
\text { aquosa e } \\
\text { ultrassom }\end{array}$ & $0,02 \%$ & 0,27 & $\begin{array}{l}\text { Nenhuma } \\
\text { melhoria }\end{array}$ & - & - & - \\
\hline
\end{tabular}




\begin{tabular}{|c|c|c|c|c|c|c|c|c|}
\hline 12 & $\begin{array}{c}\text { LI et al. } \\
\text { [1] }\end{array}$ & $\begin{array}{l}\text { Superplasti- } \\
\text { ficante com } \\
\text { NTC e OG }\end{array}$ & $\begin{array}{c}0 \text { a } 2 \% \\
\text { GO e } 0 \text { a } \\
1 \% \text { CNTs }\end{array}$ & 0,4 & - & - & $\begin{array}{c}72,7 \% \text { com OG } \\
\text { e NTCs; } 51,2 \% \\
\text { com GO e } \\
26,3 \% \text { com } \\
\text { NTCs } \\
\end{array}$ & - \\
\hline 13 & $\begin{array}{c}\text { LIU et } \\
\text { al. } \\
{[45]}\end{array}$ & $\begin{array}{l}\text { Ultrassom e } \\
\text { surfactante }\end{array}$ & $\begin{array}{c}0 \%, \\
0,025 \%, \\
0,05 \%, \\
0,1 \%, \\
0,2 \%, \\
0,4 \%, \\
0,8 \%, \\
1,6 \%, \\
3,2 \%, \mathrm{e} \\
6,4 \%\end{array}$ & $\begin{array}{l}\text { Vari- } \\
\text { ado }\end{array}$ & $\begin{array}{l}\text { Há picos de } \\
\text { ganho de } \\
\text { resistência } \\
\text { (até } 40 \%) \text {, } \\
\text { porem a ten- } \\
\text { dência de } \\
\text { crescimento } \\
\text { não é manti- } \\
\text { da }\end{array}$ & - & - & - \\
\hline 14 & $\begin{array}{l}\text { LIU et } \\
\text { al. [19] }\end{array}$ & $\begin{array}{c}\text { Solução } \\
\text { aquosa e } \\
\text { ultrassom }\end{array}$ & $0,03 \%$ & 0.44 & $\begin{array}{c}43,2 \% \text { com } \\
1,5 \% \text { NS e } \\
0,03 \% \text { OG a } \\
28 \text { dias } \\
\end{array}$ & - & $\begin{array}{l}42 \% \text { com } 1,5 \% \\
\text { NS e } 0,03 \% \text { OG } \\
\text { a } 28 \text { dias }\end{array}$ & - \\
\hline 15 & $\begin{array}{c}\text { LONG et } \\
a l . \\
{[30]}\end{array}$ & $\begin{array}{l}\text { Água e plas- } \\
\text { tificante }\end{array}$ & $\begin{array}{c}0,05,0,10 \\
\text { e } 0,20 \%\end{array}$ & 0,5 & $\begin{array}{c}26 \% \mathrm{com} \\
0,05 \%\end{array}$ & - & $\begin{array}{c}12 \% \text { com } \\
0,05 \%\end{array}$ & - \\
\hline 16 & $\begin{array}{c}\text { LONG et } \\
\text { al. }[28]\end{array}$ & $\begin{array}{c}\text { Solução } \\
\text { aquosa e } \\
\text { ultrassom }\end{array}$ & 0,1 e $0,2 \%$ & 0,5 & - & - & - & - \\
\hline 17 & $\begin{array}{l}\text { LONG et } \\
\text { al. [30] }\end{array}$ & $\begin{array}{c}\text { Solução } \\
\text { aquosa e } \\
\text { ultrassom } \\
\end{array}$ & $\begin{array}{c}0,1,0,125, \\
0,2 \mathrm{e} \\
0,25 \% \\
\end{array}$ & 0,5 & $\begin{array}{c}23,4 \% \mathrm{com} \\
0,25 \%\end{array}$ & - & $\begin{array}{c}58,9 \% \text { com } \\
0,2 \%\end{array}$ & $\begin{array}{c}24,3 \% \mathrm{com} \\
0,25 \%\end{array}$ \\
\hline 18 & $\begin{array}{c}\text { LU et al. } \\
\text { [9] }\end{array}$ & $\begin{array}{l}\text { Centrifuga- } \\
\text { ção }\end{array}$ & $\begin{array}{c}0,05,0,08 \\
0,12 \%\end{array}$ & 0,4 & $24,80 \%$ & $37,70 \%$ & $80,60 \%$ & - \\
\hline 19 & $\begin{array}{l}\text { LU L.et } \\
\text { al. [46] }\end{array}$ & Surfactante & $\begin{array}{l}0,05 \% \text { a } \\
\text { razão de } \\
\text { peso de } \\
\text { SF para } \\
\text { GO }\end{array}$ & 0,38 & $\begin{array}{c}\text { Gráficos } \\
\text { indicam me- } \\
\text { lhorias de } \\
\text { compressão } \\
\text { similares a de } \\
\text { tração. }\end{array}$ & - & $\begin{array}{l}48,4 \% \text { com } \\
\text { superplastifi- } \\
\text { cante PCE }\end{array}$ & - \\
\hline 20 & $\begin{array}{l}\text { LU Z.et } \\
\text { al. [26] }\end{array}$ & $\begin{array}{c}\text { Água em } \\
\text { concentração } \\
4 \mathrm{mg} / \mathrm{ml} \mathrm{e} \\
\text { ultrassom }\end{array}$ & $\begin{array}{c}0,02,0,04 \\
\text { e } 0,08 \%\end{array}$ & 0,48 & - & - & - & - \\
\hline 21 & $\begin{array}{l}\text { LU Z.et } \\
\text { al. [21] }\end{array}$ & $\begin{array}{c}\text { Ultrassom e } \\
\text { agitador } \\
\text { magnético }\end{array}$ & $0,05 \%$ & 0,35 & - & - & - & - \\
\hline 22 & $\begin{array}{l}\text { LU Z.et } \\
\text { al. [27] }\end{array}$ & $\begin{array}{c}\text { Solução } \\
\text { aquosa e } \\
\text { ultrassom }\end{array}$ & $\begin{array}{c}0,05 \% \text { de } \\
\text { GO e } 1 \% \\
\text { de CF }\end{array}$ & 0,2 & $8,70 \%$ & - & $14,80 \%$ & - \\
\hline 23 & $\begin{array}{l}\text { LV et al. } \\
\quad[11]\end{array}$ & Ultrassom & $\begin{array}{c}0,01,0,02, \\
0,030,04 \\
\text { e } 0,05 \%\end{array}$ & 0,37 & $38,90 \%$ & $78,60 \%$ & $60,70 \%$ & - \\
\hline 24 & $\begin{array}{l}\mathrm{LV} \text {, et al. } \\
\quad[18]\end{array}$ & Ultrassom & $\begin{array}{c}0,01,0,02, \\
0,03,0,04, \\
0,05 \mathrm{e} \\
0,06 \%\end{array}$ & 0,29 & $\begin{array}{c}127,5 \% \mathrm{com} \\
0,05 \%\end{array}$ & - & $\begin{array}{c}130,8 \% \mathrm{com} \\
0,04 \%\end{array}$ & - \\
\hline 25 & $\begin{array}{c}\mathrm{LV} \text {, et al. } \\
\text { [31] }\end{array}$ & $\begin{array}{l}\text { Água e ul- } \\
\text { trassom }\end{array}$ & $\begin{array}{c}0,01,0,02, \\
0,03,0,04 \\
\text { e } 0,05 \%\end{array}$ & 0,29 & $\begin{array}{c}56,5 \% \text { com } \\
0,03 \% \text { de OG } \\
\text { e } 0.19 \% \text { de } \\
\text { policarboxi- } \\
\text { lato }\end{array}$ & - & $\begin{array}{l}77,6 \% \text { com } \\
0.03 \% \text { de OG e } \\
0.19 \% \text { de poli- } \\
\text { carboxilato }\end{array}$ & - \\
\hline 26 & $\begin{array}{c}\text { MO- } \\
\text { HAM- } \\
\text { MED et }\end{array}$ & $\begin{array}{l}\text { Solução } \\
\text { aquosa }\end{array}$ & $\begin{array}{l}4 \mathrm{mg} \mathrm{de} \\
\text { OG/ml de } \\
\text { água }\end{array}$ & 0,34 & $\begin{array}{c}35 \% \text { aos } 28 \\
\text { dias }\end{array}$ & - & - & - \\
\hline
\end{tabular}




\begin{tabular}{|c|c|c|c|c|c|c|c|c|}
\hline & al. [8] & & & & & & & \\
\hline 27 & $\begin{array}{c}\text { MOKHT } \\
\text { AR et al. } \\
{[38]}\end{array}$ & $\begin{array}{l}\text { Solução } \\
\text { aquosa e } \\
\text { ultrassom }\end{array}$ & $\begin{array}{c}0,01,0,02, \\
0,03,0,04 \\
\text { e } 0,05 \%\end{array}$ & - & $\begin{array}{c}13 \% \text { com } \\
0,02 \%\end{array}$ & $\begin{array}{c}41 \% \text { com } \\
0,03 \%\end{array}$ & - & - \\
\hline 28 & $\begin{array}{l}\text { PAN et } \\
a l .[4]\end{array}$ & $\begin{array}{c}\text { Ultrassom e } \\
\text { agitador me- } \\
\text { cânico }\end{array}$ & $0,05 \%$ & 0,5 & $15-33 \%$ & - & $41-59 \%$ & $\begin{array}{c}\text { Pequeno } \\
\text { aumento de } \\
\text { 3,48 para } \\
3,70 \mathrm{GPa} \\
\text { em presen- } \\
\text { ça de OG } \\
\end{array}$ \\
\hline 29 & $\begin{array}{c}\text { PENG, et } \\
\text { al. [49] }\end{array}$ & $\begin{array}{c}\text { Solução de } \\
\text { água, plasti- } \\
\text { ficante e OG } \\
\text { ultrassonifi- } \\
\text { cado por } 5 \\
\text { minutos }\end{array}$ & $\begin{array}{c}0 \%, \\
0,01 \%, \\
0,03 \%, \mathrm{e} \\
0,05 \%\end{array}$ & $\begin{array}{c}0,3, \\
0,35, \\
0,4, \\
0,45 \\
\text { e } 0,5\end{array}$ & $\begin{array}{c}5,16 \% \text { com } \\
0,01 \% \text { de OG }\end{array}$ & - & $\begin{array}{c}21,9 \% \text { com } \\
0,03 \% \text { de OG }\end{array}$ & - \\
\hline 30 & $\begin{array}{c}\text { ROY et } \\
\text { al. } \\
{[47]}\end{array}$ & Ultrassom & $\begin{array}{c}0,03,0,05, \\
0,10 \mathrm{e} \\
0,20 \%\end{array}$ & 0,5 & $\begin{array}{c}90,9 \% \text { com } \\
0,05 \% \text { a } 28 \\
\text { dias }\end{array}$ & - & $\begin{array}{c}181,10 \% \text { com } \\
0,10 \% \text { a } 28 \text { dias }\end{array}$ & - \\
\hline 31 & $\begin{array}{c}\text { SHAR- } \\
\text { MA \& } \\
\text { KOTHI- } \\
\text { YAL } \\
{[40]}\end{array}$ & $\begin{array}{c}\text { Ultrassom e } \\
\text { agitador me- } \\
\text { cânico }\end{array}$ & $\begin{array}{c}0,125, \\
0,25,0,5 \mathrm{e} \\
1,0 \%\end{array}$ & 0,45 & $\begin{array}{c}\text { 63,3\% para } \\
\text { OG (14nm de } \\
\text { espessura) } \\
86,3 \% \text { para } \\
\text { OGb (3nm de } \\
\text { espessura) }\end{array}$ & - & - & - \\
\hline 32 & $\begin{array}{c}\text { SHAR- } \\
\text { MA \& } \\
\text { KOTHI- } \\
\text { YAL } \\
\text { [39] }\end{array}$ & $\begin{array}{l}\text { Água e ul- } \\
\text { trassom }\end{array}$ & $\begin{array}{l}0,1 \% \mathrm{e} \\
0,125 \%\end{array}$ & 0,45 & $\begin{array}{c}\text { Ganho má- } \\
\text { ximo de } 40 \% \\
\text { com Graphe- } \\
\text { ne Oxide } \\
\text { Nanoplatelets } \\
\text { após } 90 \text { dias }\end{array}$ & - & - & - \\
\hline 33 & $\begin{array}{l}\text { SHAR- } \\
\text { MA et al. } \\
\text { [48] }\end{array}$ & $\begin{array}{c}\text { Solução } \\
\text { aquosa e } \\
\text { presença de } \\
\text { superplastifi- } \\
\text { cante }\end{array}$ & $\begin{array}{c}0,125 \% \\
0,25 \% \\
0,50 \% \mathrm{e} \\
1 \%\end{array}$ & 0,45 & $\begin{array}{c}35 \% \text { com } \\
0,125 \% \text { de } \\
\text { OG }\end{array}$ & $\begin{array}{c}96 \% \text { com } \\
0,125 \% \text { de } \\
\text { OG }\end{array}$ & - & - \\
\hline 34 & $\begin{array}{c}\text { TONG et } \\
\text { al. }[17]\end{array}$ & Ultrassom & $0,1 \%$ & 0,54 & $\begin{array}{c}10,20- \\
13,20 \%\end{array}$ & - & - & - \\
\hline 35 & $\begin{array}{l}\text { WANG, } \\
\text { MIN et } \\
\text { al. [41] }\end{array}$ & $\begin{array}{c}\text { Ultrassom e } \\
\text { agitador me- } \\
\text { cânico }\end{array}$ & $\begin{array}{c}0,01,0,02, \\
0,03,0,04 \\
\text { e } 0,05 \%\end{array}$ & 0,33 & $\begin{array}{l}\text { Ganho máx } \\
\text { de } 25,28 \%\end{array}$ & - & $\begin{array}{c}\text { Ganho máx de } \\
56,62 \%\end{array}$ & - \\
\hline 36 & $\begin{array}{l}\text { WANG, } \\
\text { QIN et } \\
\text { al. [36] }\end{array}$ & Não revelado & $\begin{array}{c}0,01,0,02, \\
0,03,004 \\
\text { e } 0,05 \%\end{array}$ & 0,37 & $24,40 \%$ & - & $70,50 \%$ & - \\
\hline
\end{tabular}




\begin{tabular}{|c|c|c|c|c|c|c|c|c|}
\hline 37 & $\begin{array}{c}\text { YANG et } \\
\text { al. [50] }\end{array}$ & Plastificante & $\begin{array}{c}0,01 \%, \\
0,02 \%, \\
0,03 \%, \mathrm{e} \\
0,04 \%,\end{array}$ & 0,4 & $\begin{array}{c}42,30 \% \text { à } 7 \\
\text { dias }\end{array}$ & - & - & - \\
\hline 38 & $\begin{array}{c}\text { ZHAO et } \\
\text { al. [34] }\end{array}$ & $\begin{array}{c}\text { Plastificante } \\
\text { em solução } \\
\text { aquosa }\end{array}$ & $\begin{array}{c}0,011 \% \text { a } \\
0,066 \%\end{array}$ & $\begin{array}{c}0,29 \\
0,36, \\
0,45 \\
\mathrm{e} \\
0,50 \\
\end{array}$ & $34,10 \%$ & - & $30,37 \%$ & $32,37 \%$ \\
\hline 39 & $\begin{array}{c}\text { ZHAO et } \\
\text { al. [22] }\end{array}$ & Ultrassom & $0.022 \%$ & 0.42 & $27,64 \%$ & - & $26,74 \%$ & - \\
\hline 40 & $\begin{array}{c}\text { ZHAO et } \\
\text { al. [42] }\end{array}$ & Ultrassom & $\begin{array}{c}0,011, \\
0,022, \\
0,044 \mathrm{e} \\
0,066 \% \\
\end{array}$ & 0,42 & $34,10 \%$ & - & $30,37 \%$ & $32,37 \%$ \\
\hline 41 & $\begin{array}{l}\text { ZHAO et } \\
\text { al. [35] }\end{array}$ & $\begin{array}{l}\text { Solução } \\
\text { aquosa de } \\
\text { OG com } \\
\text { superplastifi- } \\
\text { cante e agita- } \\
\text { ção electro- } \\
\text { magnética e } \\
\text { ultrassônica }\end{array}$ & $\begin{array}{l}0,05, \quad 0,1, \\
0,2 \quad 0,022 \\
\text { e } 0,3 \%\end{array}$ & 0,5 & Até $25.06 \%$ & - & - & - \\
\hline 42 & $\begin{array}{c}\text { ZHAO et } \\
\text { al. }[51]\end{array}$ & $\begin{array}{l}\text { Em diversos } \\
\text { plastificantes }\end{array}$ & $\begin{array}{c}0,011 \%, \\
0,022 \%, \\
0,044 \% \text { e } \\
0,066 \%\end{array}$ & 0,42 & $\begin{array}{l}\text { Não informa } \\
\text { quantitativa- } \\
\text { mente }\end{array}$ & - & - & - \\
\hline 43 & $\begin{array}{c}\text { ZHOU et } \\
\text { al. [24] }\end{array}$ & Ultrassom & $\begin{array}{c}0,02 \% \text { OG } \\
\text { e } 0,04 \% \\
\text { NTC }\end{array}$ & 0,4 & $23,90 \%$ & - & $16,70 \%$ & - \\
\hline
\end{tabular}

\section{CONCLUSÕES}

Este trabalho apresentou um processo estruturado de pesquisa acadêmica para composição de um referencial teórico: o ProKnow-C. Este processo permitiu a obtenção de um portfólio bibliográfico abrangente, representativo e relevante sobre os efeitos da adição do óxido de grafeno em compósitos de cimento Portland.

O procedimento ProKnow-C possibilitou, em sua fase inicial, selecionar, a partir de uma amostra bruta de 1354 artigos, os 47 artigos mais relevantes que apresentavam as alterações nas propriedades mecânicas, comportamento reológico e microestrutura de compósitos de cimento com adição de OG, bem como técnicas de dispersão utilizadas.

A segunda fase do ProKnow-C consistiu na análise sistêmica dos artigos, tendo sido realizada a partir da visão particular de conhecimento dos pesquisadores. Essa visão é estruturada em quatro lentes de pesquisa.

A partir da definição destas lentes de pesquisa, buscou-se selecionar e extrair as informações de interesse dos artigos analisados de forma precisa. Ao final do processo, as informações obtidas foram categorizadas e apresentadas na Tabela 4. Também foram identificadas oportunidades futuras de pesquisa, retratadas na Tabela 5: 
Tabela 5: Resumo dos principais resultados encontrados no portfólio bibliográfico.

\begin{tabular}{l|l|l}
\hline ID & LENTES & OPORTUNIDADES \\
\hline 1 & Métodos de dispersão & $\begin{array}{l}\text { Mesclar diferentes técnicas de dispersão para permitir maiores concentrações de } \\
\text { OG. Verificar a eficiência de outros aditivos na dispersão do OG, como lignosulfo- } \\
\text { nato ou polinaftaleno sulfonato. }\end{array}$ \\
\hline 2 & Microestrutura & $\begin{array}{l}\text { Produzir imagens do arranjo cristalino de compósitos cimentícios com adição de } \\
\text { OG. Produzir imagens da zona de interface pasta-agregado. }\end{array}$ \\
\hline 3 & Comportamento reológico & $\begin{array}{l}\text { Realizar estudos sobre o tempo de pega de compósitos cimentícios com adição de } \\
\text { OG. Utilizar o reômetro digital para verificação da medida de fluidez obtida no } \\
\text { teste de mini-slump. }\end{array}$ \\
\hline 4 & Propriedades mecânicas & $\begin{array}{l}\text { Realizar mais estudos sobre os efeitos da adição de OG no módulo de elasticidade } \\
\text { de compósitos cimentícios. }\end{array}$ \\
\hline \multicolumn{2}{l}{ Outros } & Verificar os efeitos da adição de OG em concretos. \\
\hline
\end{tabular}

Com este trabalho, busca-se incentivar o uso dos processos estruturados para a seleção e evidenciação de artigos, criando referenciais teóricos consistentes para o suporte de pesquisas futuras.

\section{AGRADECIMENTOS}

Os autores gostariam de agradecer a CAPES, o CNPq, a FAPEMIG e o CEFET-MG pelo apoio financeiro e técnico fornecido para o desenvolvimento deste trabalho.

\section{BIBLIOGRAFIA}

[1] LI, X., WEI, W., QIN, H., et al. Co-effects of graphene oxide sheets and single wall carbon nanotubes on mechanical properties of cement. Journal of Physics and Chemistry of Solids, v. 85, p. 39-43, 2015.

[2] HOU, D.,i et al. Reactive molecular dynamics and experimental study of graphene-cement composites: Structure, dynamics and reinforcement mechanisms. Carbon, v. 115, p. 188-208, 2017.

[3] SILVA, R.A., et al. Enhanced properties of cement mortars with multilayer graphene nanoparticles. Construction and Building Materials, v. 149, p. 378-385, set. 2017.

[4] PAN, Z., HE, L., QIU, L., et al. Mechanical properties and microstructure of a graphene oxide-cement composite. Cement and Concrete Composites, v. 58, p. 140-147, 2015.

[5] ENSSLIN, L., ENSSLIN, S.R., PACHECO, G.C. Um estudo sobre segurança em estádios de futebol baseado na análise bibliométrica da literatura internacional. Perspectivas em Ciência da Informação, v. 17, 2012. [6] CHAVES, L.C., et al. Sistemas de apoio à decisão: mapeamento e análise de conteúdo. Revista Eletrônica de Ciência Administrativa, v. 12, n. 1, p. 6-22, 2012.

[7] AZEVEDO, R.C.D. Um modelo para gestão de risco na incorporação de imóveis usando metodologia multicritério para apoio à decisão-construtivista (MCDA-C): UNIVERSIDADE FEDERAL DE SANTA CATARINA 2013.

[8] MOHAMMED, A., et al. Incorporating graphene oxide in cement composites: A study of transport properties. Construction and Building Materials, v. 84, p. 341-347, 2015.

[9] LU, C., et al. Effect of graphene oxide on the mechanical behavior of strain hardening cementitious composites. Construction and Building Materials, v. 120, p. 457-464, 2016.

[10] LIN, C., WEI, W., HU, et al. Catalytic behavior of graphene oxide for cement hydration process. Journal of Physics and Chemistry of Solids, v. 89, p. 128-133, 2016.

[11] LV, S., et al. Effect of graphene oxide nanosheets of microstructure and mechanical properties of cement composites. Construction and Building Materials, v. 49, p. 121-127, 2013.

[12] LACERDA, R.T.O., ENSSLIN, L.; ENSSLIN, S.R.. Uma análise bibliométrica da literatura sobre estratégia e avaliação de desempenho. Gestão \& Produção, v. 19, n. 1, p. 59-78, 2012.

[13] AZEVEDO, R.C., ENSSLIN, L., JUNGLES, A.E.. A Review of Risk Management in Construction: Opportunities for Improvement. Modern Economy, v. 05, n. 04, p. 367-383, 2014.

[14] WAICZYK, C., ENSSLIN, E.R. Avaliação de produção científica de pesquisadores: mapeamento das publicações científicas. Revista Contemporânea de Contabilidade, v. 10, n. 20, p. 97-112, 2013. 
[15] HORSZCZARUK, E., et al. Nanocomposite of cement/graphene oxide - Impact on hydration kinetics and Young's modulus. Construction and Building Materials, v. 78, p. 234-242, 2015.

[16] GONG, K., ASCE, S.M., et al. Reinforcing Effects of Graphene Oxide on Portland Cement Paste Reinforcing Effects of Graphene Oxide on Portland Cement Paste. Journal of Materials in Civil Engineering, v. 27, n. 2, p. 1-6, 2015.

[17] TONG, T., et al. Investigation of the effects of graphene and graphene oxide nanoplatelets on the microand macro-properties of cementitious materials. Construction and Building Materials, v. 106, p. 102-114, 2016.

[18] LV, S., LIU, J., SUN, T., et al. Effect of GO nanosheets on shapes of cement hydration crystals and their formation process. Construction and Building Materials, v. 64, p. 231-239, 2014.

[19] LIU, H., YU, Y., LIU, H., et al. Hybrid effects of nano-silica and graphene oxide on mechanical properties and hydration products of oil well cement. Construction and Building Materials, v. 191, p. 311-319, 2018. [20] LI, X., WANG, L., LIU, Y., et al. Dispersion of graphene oxide agglomerates in cement paste and its effects on electrical resistivity and flexural strength. Cement and Concrete Composites, v. 92, p. 145-154, 2018.

[21] LU, Z., HANIF, A., SUN, G., et al. Highly dispersed graphene oxide electrodeposited carbon fiber reinforced cement-based materials with enhanced mechanical properties. Cement and Concrete Composites, v. 87, p. 220-228, 2018.

[22] ZHAO, L., et al. Investigation of the effectiveness of PC@GO on the reinforcement for cement composites. Construction and Building Materials, v. 113, p. 470-478, 2016.

[23] GAO, Y., JING, H.W., CHEN, S.J., et al. Influence of ultrasonication on the dispersion and enhancing effect of graphene oxide-carbon nanotube hybrid nanoreinforcement in cementitious composite. Composites Part B: Engineering, v. 164, p. 45-53, 2019.

[24] ZHOU, C., LI, F., HU, J., et al. Enhanced mechanical properties of cement paste by hybrid graphene oxide/carbon nanotubes. Construction and Building Materials, v. 134, p. 336-345, 2017.

[25] CHEN, Z., ZHOU, X., WANG, X., et al. Mechanical behavior of multilayer GO carbon-fiber cement composites. Construction and Building Materials, v. 159, p. 205-212, 2018.

[26] LU, Z., LI, X., HANIF, A., et al. Early-age interaction mechanism between the graphene oxide and cement hydrates. Construction and Building Materials, v. 152, p. 232-239, 2017.

[27] LU, Z., HOU, D., HANIF, A., et al. Comparative evaluation on the dispersion and stability of graphene oxide in water and cement pore solution by incorporating silica fume. Cement and Concrete Composites, v. 94, p. 33-42, 2018.

[28] LONG, W.J., GU, Y., XIAO, B.X., et al. Micro-mechanical properties and multi-scaled pore structure of graphene oxide cement paste: Synergistic application of nanoindentation, X-ray computed tomography, and SEM-EDS analysis. Construction and Building Materials, v. 179, p. 661-674, 2018.

[29] HE, J., DU, S., YANG, Z., et al. Laboratory investigation of graphene oxide suspension as a surface sealer for cementitious mortars. Construction and Building Materials, v. 162, p. 65-79, 2018.

[30] LONG, W.J., WEI, J.J., XING, F., et al. Enhanced dynamic mechanical properties of cement paste modified with graphene oxide nanosheets and its reinforcing mechanism. Cement and Concrete Composites, v. 93, p. 127-139, 2018.

[31] LV, S.H., et al. Fabrication of polycarboxylate/graphene oxide nanosheet composites by copolymerization for reinforcing and toughening cement composites. Cement and Concrete Composites, v. 66, p. 1-9, 2016.

[32] YANG, H., et al. Composites : Part A A critical review on research progress of graphene / cement based composites. Composites Part A, v. 102, p. 273-296, 2017.

[33] LI, G., YUAN, J.B., ZHANG, Y.H., et al. Microstructure and mechanical performance of graphene reinforced cementitious composites. Composites Part A: Applied Science and Manufacturing, v. 114, p. 188-195, 2018.

[34] ZHAO, L., GUO, X., LIU, Y., et al. Hydration kinetics, pore structure, 3D network calcium silicate hydrate, and mechanical behavior of graphene oxide reinforced cement composites. Construction and Building Materials, v. 190, p. 150-163, 2018.

[35] ZHAO, L., GUO, X., LIU, Y., et al. Investigation of dispersion behavior of GO modified by different water reducing agents in cement pore solution. Carbon, v. 127, p. 255-269, 2018.

[36] WANG, Q, et al. Influence of graphene oxide additions on the microstructure and mechanical strength of cement. New Carbon Materials, v. 30, n. 4, p. 349-356, 2015.

[37] LI, X., LU, Z., CHUAH, S., et al. Effects of graphene oxide aggregates on hydration degree, sorptivity, and tensile splitting strength of cement paste. Composites Part A: Applied Science and Manufacturing, 2017. 
[38] MOKHTAR, M.M., ABO-EL-ENEIN, S.A., HASSAAN, M.Y. Mechanical performance, pore structure and micro-structural characteristics of graphene oxide nano platelets reinforced cement. Construction and Building Materials, v. 138, p. 333-339, 2017.

[39] SHARMA, S., KOTHIYAL, N.C., Comparative effects of pristine and ball-milled graphene oxide on physico-chemical characteristics of cement mortar nanocomposites. Construction and Building Materials, v. 115, p. 256-268, 2016.

[40] SHARMA, S., KOTHIYAL, N.C. Influence of graphene oxide as dispersed phase in cement mortar matrix in defining the crystal patterns of cement hydrates and its effect on mechanical, microstructural and crystallization properties. RSC Advances, v. 5, n. 65, p. 52642-52657, 2015.

[41] WANG, M., et al. Study on the three dimensional mechanism of graphene oxide nanosheets modified cement. Construction and Building Materials, v. 126, p. 730-739, 2016.

[42] ZHAO, L., GUO, X., GE, C., et al. Mechanical behavior and toughening mechanism of polycarboxylate superplasticizer modified graphene oxide reinforced cement composites. Composites Part B: Engineering, v. 113, p. 308-316, 2017.

[43] LI, X., LIU, Y.M., LI, W.G., et al. Effects of graphene oxide agglomerates on workability, hydration, microstructure and compressive strength of cement paste. Construction and Building Materials, v. 145, p. 402-410, 2017.

[44] LI, X., KORAYEM, A.H., LI, C., et al. Incorporation of graphene oxide and silica fume into cement paste: A study of dispersion and compressive strength. Construction and Building Materials, v. 123, p. 327$335,2016$.

[45] LIU, Q., XU, Q., YU, Q., et al. Experimental investigation on mechanical and piezoresistive properties of cementitious materials containing graphene and graphene oxide nanoplatelets. Construction and Building Materials, v. 127, p. 565-576, 2016.

[46] LU, L., ZHAO, P., LU, Z. A short discussion on how to effectively use graphene oxide to reinforce cementitious composites. Construction and Building Materials, v. 189, p. 33-41, 2018.

[47] ROY, R., MITRA, A., GANESH, A.T., et al. Effect of Graphene Oxide Nanosheets dispersion in cement mortar composites incorporating Metakaolin and Silica Fume. Construction and Building Materials, v. 186, p. 514-524, 2018.

[48] SHARMA, S., SUSAN, D., KOTHIYAL, N.C., et al. Graphene oxide prepared from mechanically milled graphite: Effect on strength of novel fly-ash based cementitious matrix. Construction and Building Materials, v. 177, p. 10-22, 2018.

[49] PENG, H., GE, Y., CAI, C.S., et al. Mechanical properties and microstructure of graphene oxide cement-based composites. Construction and Building Materials, v. 194, p. 102-109, 2019.

[50] YANG, H., MONASTERIO, M., CUI, H., et al. Experimental study of the effects of graphene oxide on microstructure and properties of cement paste composite. Composites Part A: Applied Science and Manufacturing, v. 102, p. 263-272, 2017.

[51] ZHAO, L., et al. Mechanical behavior and toughening mechanism of polycarboxylate superplasticizer modified graphene oxide reinforced cement composites. Composites Part B: Engineering, v. 113, p. 308-316, 2018.

\section{ORCID}

Vanessa Vilela Rocha

Ricardo Augusto dos Santos Horta

Júnia Nunes de Paula

Péter Ludvig http://orcid.org/0000-0002-6494-2019

https://orcid.org/0000-0002-2552-0972

https://orcid.org/0000-0002-8522-2627

https://orcid.org/0000-0001-6525-8545 